\title{
Caffeine Exposure and the Risk of Parkinson's Disease: A Systematic Review and Meta-Analysis of Observational Studiess
}

\author{
João Costa ${ }^{\mathrm{a}, \mathrm{b}, *}$, Nuno Lunet ${ }^{\mathrm{c}, \mathrm{d}}$, Catarina Santos ${ }^{\mathrm{c}, \mathrm{d}}$, João Santos ${ }^{\mathrm{a}}$ and António Vaz-Carneiro ${ }^{\mathrm{a}}$ \\ ${ }^{\mathrm{a}}$ Center for Evidence-Based Medicine, Faculty of Medicine, University of Lisbon, Portugal \\ ${ }^{\mathrm{b}}$ Centro de Investigación Biomédica en Red de Enfermedades Neurodegenerativas (CIBERNED), Spain \\ ${ }^{\mathrm{c}}$ Department of Hygiene and Epidemiology, Porto University Medical School, Porto, Portugal \\ ${ }^{\mathrm{d}}$ Institute of Public Health of the University of Porto (ISPUP), Porto, Portugal
}

\begin{abstract}
Several studies conducted worldwide report an inverse association between caffeine/coffee consumption and the risk of developing Parkinson's disease (PD). However, heterogeneity and conflicting results between studies preclude a correct estimation of the strength of this association. We conducted a systematic review and meta-analysis of published epidemiological studies to better estimate the effect of caffeine exposure on the incidence of PD. Data sources searched included Medline, LILACS, Scopus, Web of Science and reference lists, up to September 2009. Cohort, case-control and cross-sectional studies were included. Three independent reviewers selected the studies and extracted the data on to standardized forms. Twenty-six studies were included: 7 cohort, 2 nested case-control, 16 case-control, and 1 cross-sectional study. Quantitative data synthesis of the most precise estimates from each study was accomplished through random effects meta-analysis. Heterogeneity was quantified using the $\mathrm{I}^{2}$ statistic. The summary RR for the association between caffeine intake and PD was 0.75 [95\% Confidence Interval (95\%CI): 0.68-0.82], with low to moderate heterogeneity $\left(\mathrm{I}^{2}=28.8 \%\right)$. Publication bias for case-control/cross-sectional studies may exist (Egger's test, $p=0.053$ ). When considering only the cohort studies, the RR was 0.80 (95\%CI: $0.71-90 ; \mathrm{I}^{2}=8.1 \%$ ). The negative association was weaker when only women were considered $\left(\mathrm{RR}=0.86,95 \% \mathrm{CI}\right.$ : $\left.0.73-1.02 ; \mathrm{I}^{2}=12.9 \%\right)$. A linear relation was observed between levels of exposure to caffeine and the RR estimates: RR of 0.76 (95\%CI: $0.72-0.80 ; \mathrm{I}^{2}=35.1 \%$ ) per $300 \mathrm{mg}$ increase in caffeine intake. This study confirm an inverse association between caffeine intake and the risk of PD, which can hardly by explained by bias or uncontrolled confounding.
\end{abstract}

Keywords: Caffeine, meta-analysis, Parkinson's disease, relative risk, risk assessment

\section{INTRODUCTION}

Parkinson's disease (PD) is the second most common neurodegenerative disease with an estimated worldwide prevalence of 0.5 to $4 \%$ among the elderly [1]. The underlying neuropathological lesion is the degeneration of the pigmented neurons of the substantia nigra, locus caeruleus, and other brain stem dopaminer-

* Correspondence to: João Parracho da Costa, MD, PhD, Centro de Estudos de Medicina, aseada na Evidência (CEMBE), Piso 3, Faculdade de Medicina de Lisboa, Av Prof Egas Moniz., 1649-028 Lisboa, Portugal. Tel./Fax: +351 217940424; E-mail: joaoncosta@sapo.pt. gic cell groups, with the subsequent loss of dopaminergic neurons terminals in the striatum. The continuous depletion of dopamine is responsible for most of the debilitating motor disturbances of the disease. The cardinal signs include bradykinesia, rigidity, rest tremor, gait disturbances, and postural instability [2].

There is not a single cause of PD, and multiple etiological factors with complex interactions are thought to be responsible for the development and progression of the disease $[3,4]$. The results of genetic and epidemiological studies suggest that genetic factors are particularly important in early-onset cases of PD $[5,6]$ while the environmental component is probably more 
relevant in the development of PD at older ages (above 50 years) [1].

There is a long list of environmental and lifestyle factors that have been associated with PD, either as risk or protective factors for the development of the disease. Infections, place of birth at early life, drinking wellwater, occupational exposure to welding, heavy metals or pesticides, and lack of vigorous exercise have all been referred to in the literature as putative risk factors [7-12]. On the other hand, smoking and consumption of coffee, tea, or nonsteroidal anti-inflammatory drugs are thought as possible protective factors [13]. Among all these factors, the most well studied in the literature are cigarette smoking and lifetime coffee consumption. In fact, the associations between smoking and coffee and lower risk of PD were first mentioned in the literature many years ago $[14,15]$. Since then, several large epidemiological studies conducted in the US, Europe, and Asia reported a dose-dependent inverse association between exposure to these factors and the risk of developing PD. These inverse associations were corroborated in family-based case-control studies, thus emphasizing smoking and caffeine as important covariates in any genetic or epidemiological studies of PD [16].

The strength of the evidence for the described inverse associations is weaker for coffee/caffeine than for smoking, because there are fewer studies and the magnitude of the effect is lower. A meta-analysis by Hernán and colleagues, published 8 years ago, found a polled relative risk of PD of about $60 \%$ and $30 \%$ lower among smokers and coffee drinkers in comparison to nonsmokers and non-coffee drinkers, respectively [17]. These results were based on a large number of studies (44 case-control and 4 cohort studies) for the smoking association, but on only 13 studies ( 8 case-control and 5 cohort studies) for coffee drinking. In addition, there is heterogeneity between studies results, and some of the studies published since then failed to show a significant negative association [18-21] or suggested significant differences between men and women, especially postmenopausal women on estrogen replacement therapy [22,23]. There are also conflicting findings in the few available data about the putative association of caffeine and the rate of progression of PD or the age of motor symptoms onset. Recent studies failed to identify any consistent relation either with the rate of progression $[24,25]$ or the age of motor symptoms onset [26, 27].

In view of the results of these more recent studies, we conducted a systematic review and a meta-analysis of the literature to quantify the association between caffeine intake and PD.

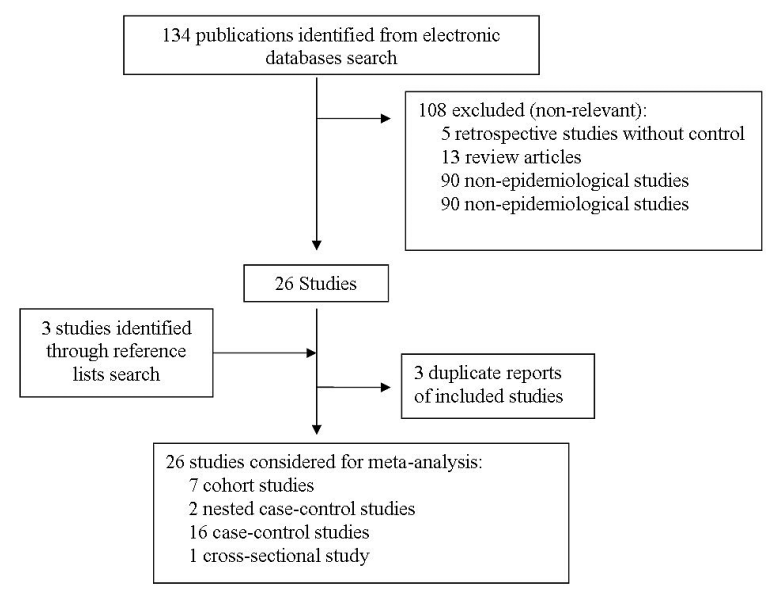

Fig. 1. Systematic review flow-chart.

\section{MATERIALS AND METHODS}

\section{Search strategy and selection criteria}

Potential eligible studies were identified through an electronic search of the databases Medline, LILACS (Latin America and Caribbean), Scopus and Web of Science (Fig. 1). The latest search of these databases was performed on September 2009. The search strategy for Medline combined the terms (coffee OR caffeine) with (Parkinson or Parkinson disease) together with a search filter developed for the retrieval of epidemiological studies (Cohort Studies OR Case Control Studies OR Prospective Studies OR Follow-Up Studies OR Cross-Sectional Studies OR Retrospective studies OR Epidemiological OR Incidence OR Risk Factors OR Risk Assessment OR Risk Reduction OR Relative Risk OR Behavior Regression Analysis OR Multivariate Analysis OR Proportional Hazards Models). All terms were searched as MeSH (Medical Subjects Headings) and free-text words. Moreover, the reference lists of relevant studies were cross-checked for potential additional studies not identified by the electronic search. We screened titles, keywords, and abstracts and obtained full copies of potentially suitable reports. There were no language restrictions and reports published as a full paper or abstract were considered as long as relevant data could be extracted.

The studies with cohort, case-control or crosssectional designs that evaluated the relation between exposure to coffee/caffeine and the risk of PD (all diagnostic criteria were considered) or PD mortality were eligible for the systematic review. We excluded studies addressing the effects of short-term exposure to coffee 
or caffeine and those that evaluated associations other than the risk of PD, such as the rate of progression. No studies were excluded a priori for weakness of design or data quality.

\section{Data extraction}

Three authors independently assessed the identified studies (JC, JS, and CS). Study details were obtained independently, written on predefined standardized forms, and cross checked for accuracy. Disagreements were resolved by consensus after repeated examination of the articles.

The information abstracted included the study characteristics (publication year, country of origin, study period, study design and length of follow-up), participant characteristics (number, age and gender), selection of cases and controls in case-control studies, assessment of coffee/caffeine intake and outcome (criteria for definition of PD or PD mortality), adjustment for potential confounders, and estimates of the association between different measures of coffee/caffeine exposure and PD.

When different risk estimates were available in the same publication, we opted for those that reflected the greatest degree of control for potential confounder, to the largest number of categories of exposure among caffeine consumers, or to the most comprehensive assessment of caffeine intake, applying these criteria consecutively. If results were provided separately for different caffeine-containing beverages or food items we opted for those referring to coffee consumption. Stratumspecific Relative Risk (RR) estimates [according to gender, use of Hormonal Replacement Therapy (HRT), or genetic polymorphisms related to caffeine metabolization] were extracted whenever available. Ross and colleagues [28] provided adjusted RRs but the highest category of exposure was used as reference and crude RR estimates were computed using the lowest exposure as reference. The crude estimates, however, were not meaningfully different from the adjusted ones. Ascherio and coworkers [29] provided RR estimates for both coffee and caffeine intake. The latter was provided graphically and the former was extracted, but there were no meaningful differences in the RR estimates per exposure level for coffee and caffeine.

Three studies [15,30,31] had matched case-control designs and did not provide Odds Ratio (OR) estimates for the association between caffeine intake and PD, or the data necessary for the calculation of valid estimates. Since the OR for drinkers vs. non-drinkers computed using information from these studies is available in the meta-analysis by Hérnan et al. [17], which reported to have contacted the authors for additional information, we used the estimates they computed. Haack and collaborators [32] provided the OR for drinkers vs. nondrinkers in their report but it is slightly different from the provided by Hérnan et al. [17] and we used the latter in our meta-analyses.

When there was more than one publication for the same study, we used the one providing more detailed information on the relation between coffee/caffeine intake and PD, using the same criteria applied when more than one estimate was available from the same study, or referring to the longer follow-up (for cohort designs).

The samples evaluated by Ascherio and colleagues in 2001 [29] and in 2003 [33] overlap partially and we used the results referring to males presented in the study published in 2001, as these are not available in the 2003 study, and the results referring to females published in 2003.

\section{Data synthesis}

Each study is summarized in Table 1 and Fig. 2. The forest plot corresponding to Fig. 2 represents the RR estimates provided in each study for the association between caffeine intake and PD. Several estimates from the same study may be provided, referring to different exposure levels or to stratum-specific analyses.

Quantitative data synthesis was accomplished through random effects meta-analysis (DerSimonian and Laird method) (Fig. 3). Relative risks (cumulative incidence ratios or incidence density ratios) and ORs were treated the same and are referred to as RR. A cumulative random effects meta-analysis (Fig. 4) was conducted to allow a better understanding of the time trends in the understanding of the relation between caffeine intake and PD.

Summary estimates for exposure to caffeine were computed considering the individual RR estimates corresponding to coffee, coffee, and tea or caffeine intake (from caffeinated beverages or caffeinated beverages and chocolate), as available from each article, under the assumption that coffee is the main contributor for caffeine intake.

Since more than one RR estimate was available from several studies, only the most precise measures of association were used from each report (except for stratumspecific estimates, which were considered separately as if obtained from different studies). This criterion was followed for selection of a single estimate per study 


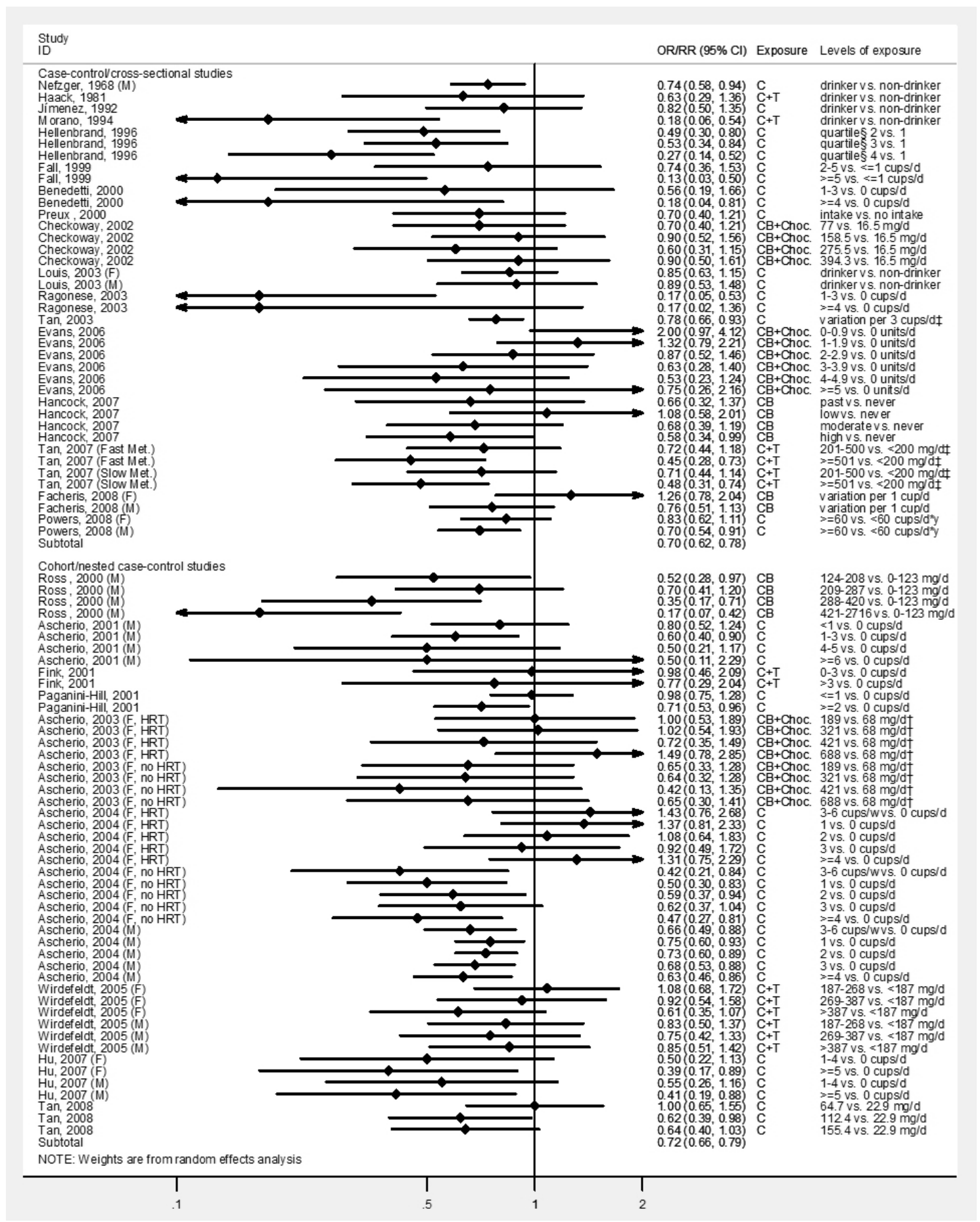

Fig. 2. Relative Risk estimates for the association between caffeine and Parkinson's disease, according to sources of caffeine intake and levels of exposure. Legend: ID - Identification; OR/RR - Odds Ratio/Relative Risk; M - Male; F - Female; C - coffee; T - tea; C+T - coffee and tea; $\mathrm{CB}$ - caffeinated beverages; $\mathrm{CB}+$ Choc. - caffeinated beverages and chocolate; Fast Met. - Fast metabolizers; Slow Met. - Slow metabolizers; HRT - Hormonal Replacement Therapy; $d$ - day; $w$ - week; $\dagger$ - the exposures correspond to the median of each fifth of the distribution; $\ddagger-$ consumption in $\mathrm{mg} / \mathrm{day}$ for 10 years; $\S$ - levels of exposure not further specified 


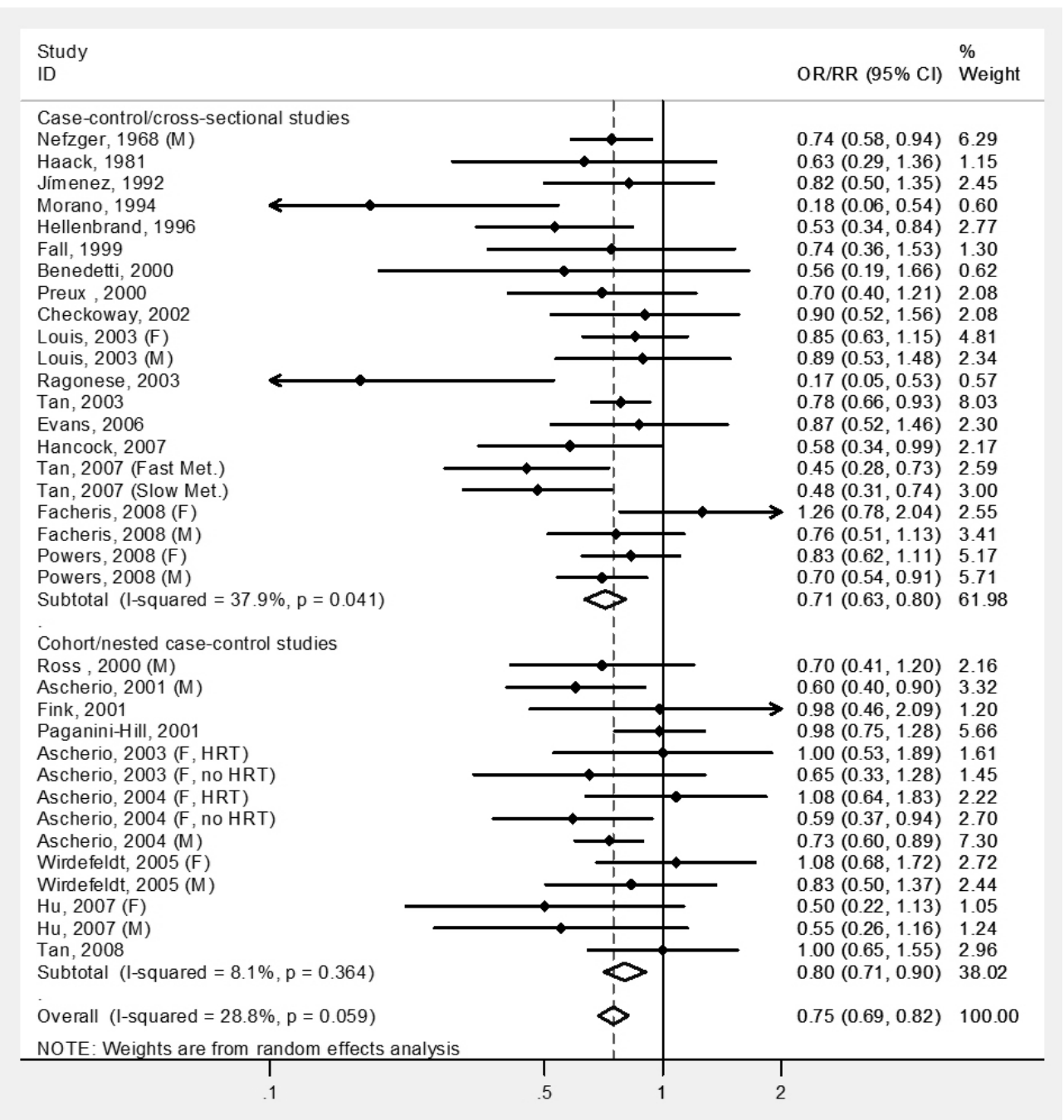

Fig. 3. Meta-analysis for the association between caffeine and Parkinson's disease, including the most precise RR estimates from each individual study. Legend: ID - Identification; OR/RR - Odds Ratio/Relative Risk; M - Male; F - Female; Fast Met. - Fast metabolizers; Slow Met. - Slow metabolizers; HRT - Hormonal Replacement Therapy.

when RRs were provided for different categories of exposure. If the precision of RR estimates was the same for more than one category we conservatively chose the one corresponding to the RR closest to 1 .

The dose response relation between caffeine intake and PD was assessed through visual inspection of a scatter plot representing the RR estimates from each study (in a log scale) according to the exposure to caffeine (Fig. 5), and quantified by weighted least squares regression (WLS). All the RR estimates (for each level of exposure and for each stratum-specific analysis) obtained from studies providing RR estimates for at least two categories of exposure compared with the referent were plotted and included in the regression model.
This information was obtained from 15 studies $[19,20$, $22,23,26,28,29,33-40]$, corresponding to 69 RR estimates. The exposures corresponding to each RR estimate were those provided by the authors (e.g. median of each distribution quantile) or assumed to correspond to the midpoint of each index category range subtracted by the midpoint of the reference category range. For this purpose, we assumed that the open-ended upper category had the amplitude of the preceding stratum. The caffeine intake corresponding to each category of exposure or the information to compute it was provided by most studies. For three studies conducted in the USA $[22,26,36]$ we assumed that a cup of coffee corresponds to $137 \mathrm{mg}$ of caffeine (based on the estimates 


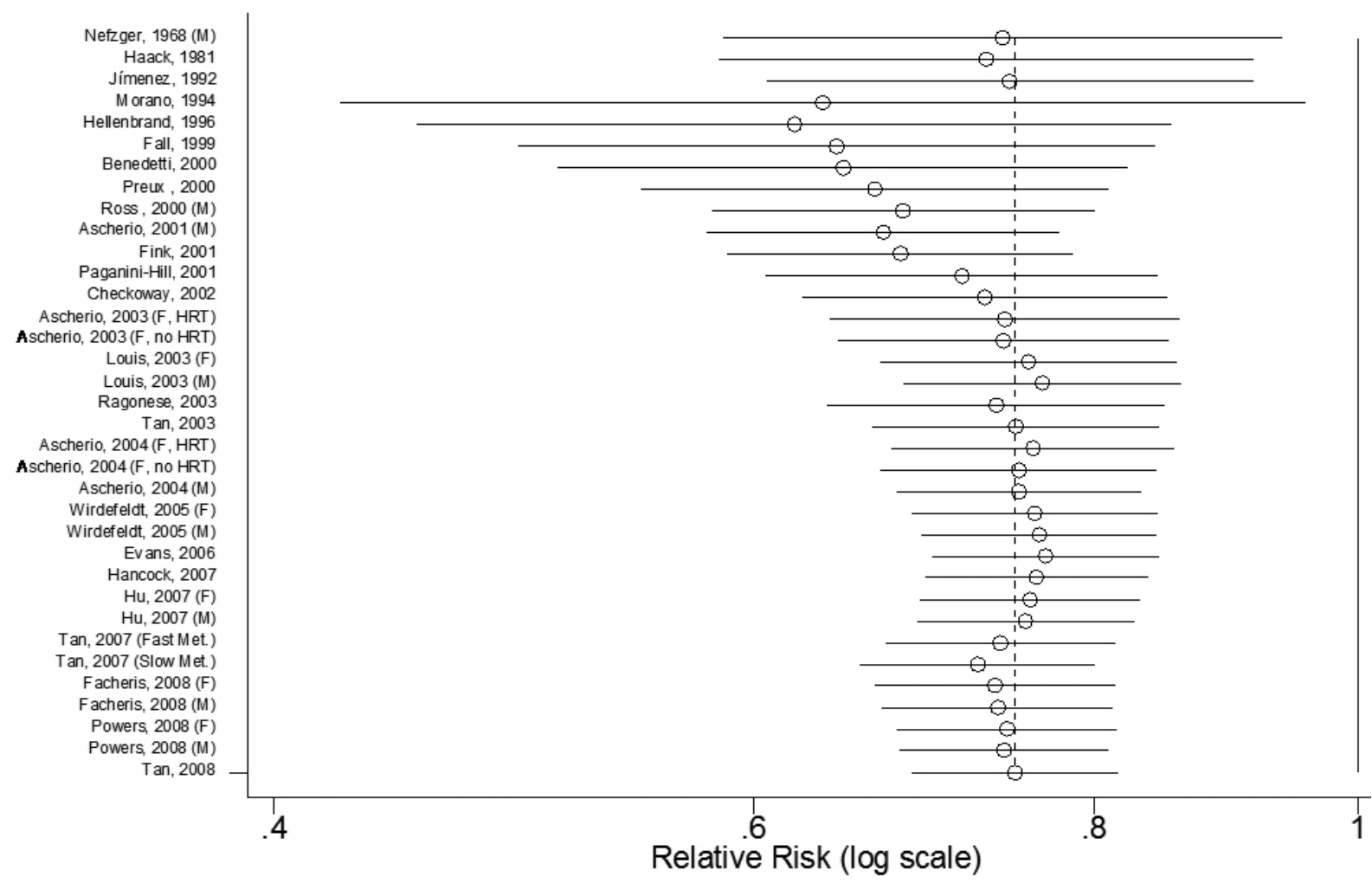

Fig. 4. Cumulative meta-analysis for the association between caffeine and Parkinson's disease, including the most precise Relative Risk estimates from each individual study. Legend: M - Male; F - Female; Fast Met. - Fast metabolizers; Slow Met. - Slow metabolizers; HRT - Hormonal Replacement Therapy.

used in other studies conducted by Ascherio et al.) and for one Italian study [37] the caffeine contents of a cup was assumed to be $75 \mathrm{mg}$ (under the assumption that espresso coffee was more frequently consumed in this setting).

In all analyses heterogeneity was quantified using the $\mathrm{I}^{2}$ statistic [41]. Publication and publication-related biases were examined through visual inspection of the funnel plot (Fig. 6). The Begg adjusted rank correlation [42] and the Egger's regression asymmetry test [43] were used for further assessment of these biases through hypothesis testing. All analyses were conducted with STATA ${ }^{\circledR}$, version 9.2 .

\section{RESULTS}

\section{Systematic review}

The search yielded a total of 134 reports (Fig. 1). A total of 26 epidemiological studies met criteria for inclusion in the systematic review, including 7 cohort $[22$,
23,28,29,33,35,40,44], 2 nested case-control [20,36], 16 case-control $[15,16,18,19,21,26,30-32,34,37-39$, 45-47] and one cross-sectional study [48]. The main characteristics of the studies and the respective results on the relation between caffeine intake and cognitive impairment are summarized in Table 1 and Fig. 2.

The publication year ranged from 1968 to 2008 . The studies were conducted mainly in the USA (13 out of $26[15,16,19,21,22,26,29,32,33,36,47,48]$, one of which in an Asian population [28]); in Europe (two in Spain [30,31], two in Sweden [20,?], one in Finland [23], one in France [18], one in Germany [45], one in Italy [37], one in the United Kingdom [38]); and in China $[39,40,46]$.

Among the case-control studies, information on caffeine intake obtained from proxies or exclusion of cognitively impaired subjects was referred to in $4[21,32$, $34,46]$ and 3 reports $[19,38,45]$, respectively. The study by Louis and colleagues [48] used both these strategies to minimize information bias. An accurate definition of the study base is not always possible with the information provided by the authors, but at least 5 were hospital based $[15,30,31,37,38]$. In cohort designs, the 


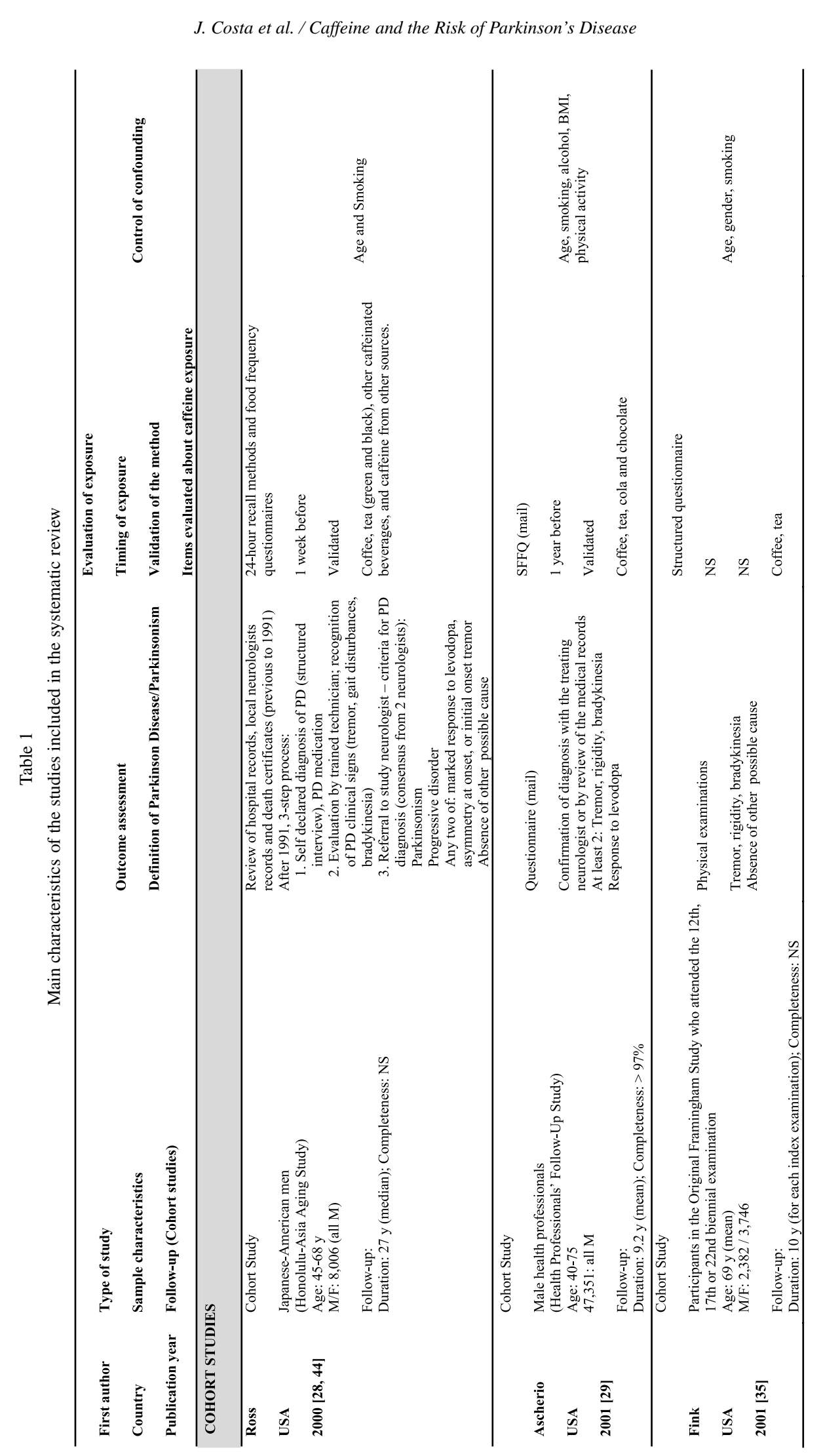




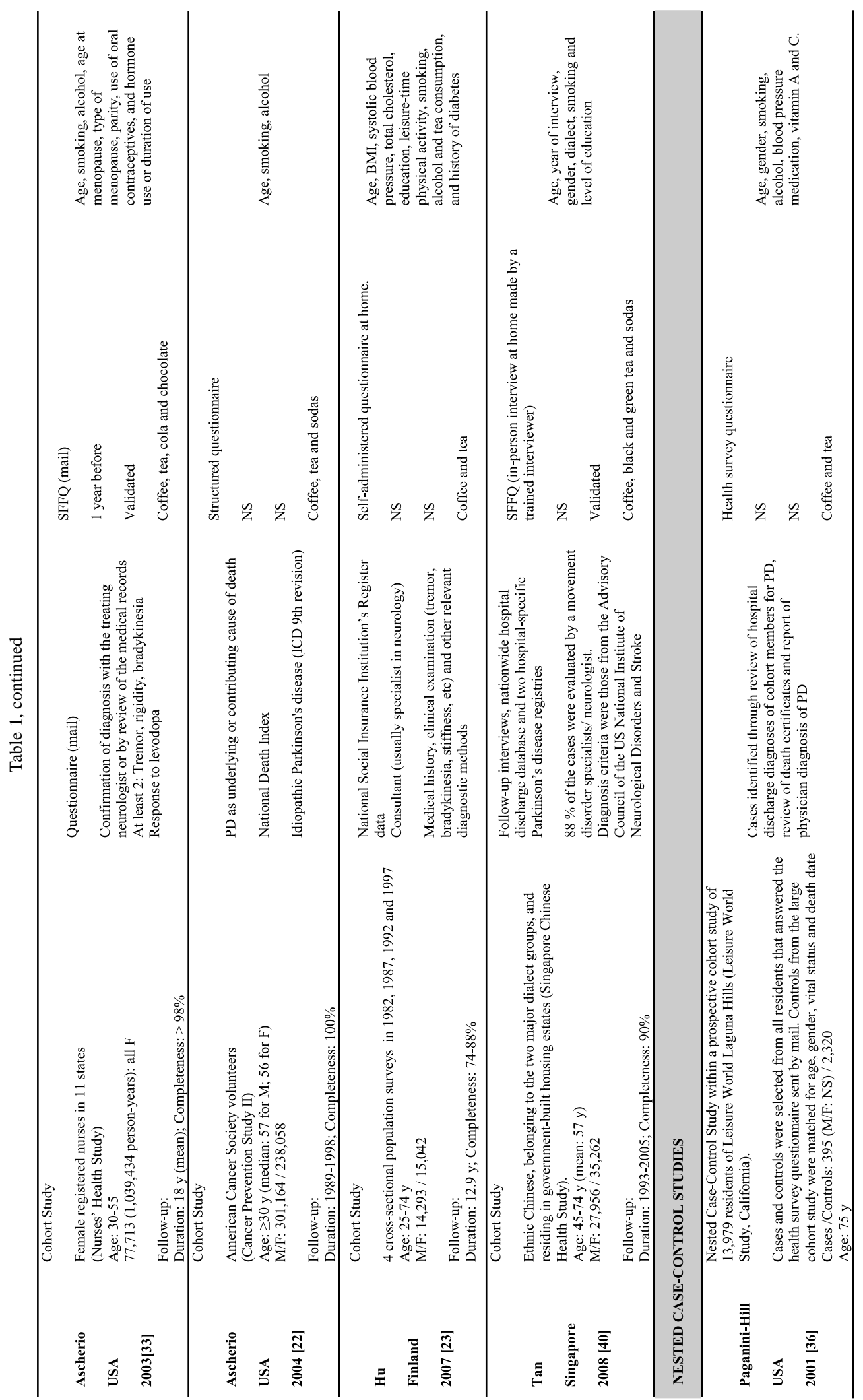




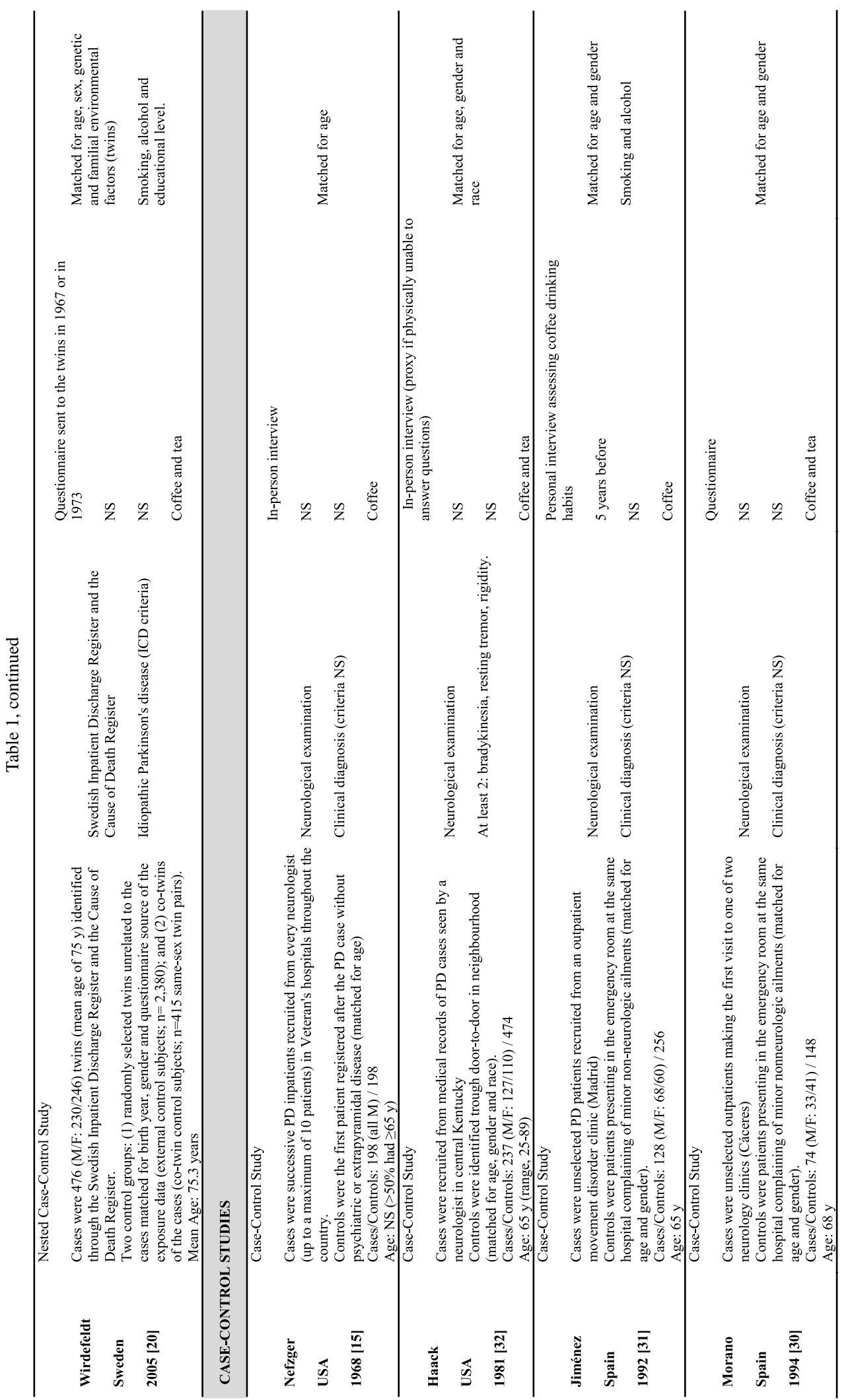




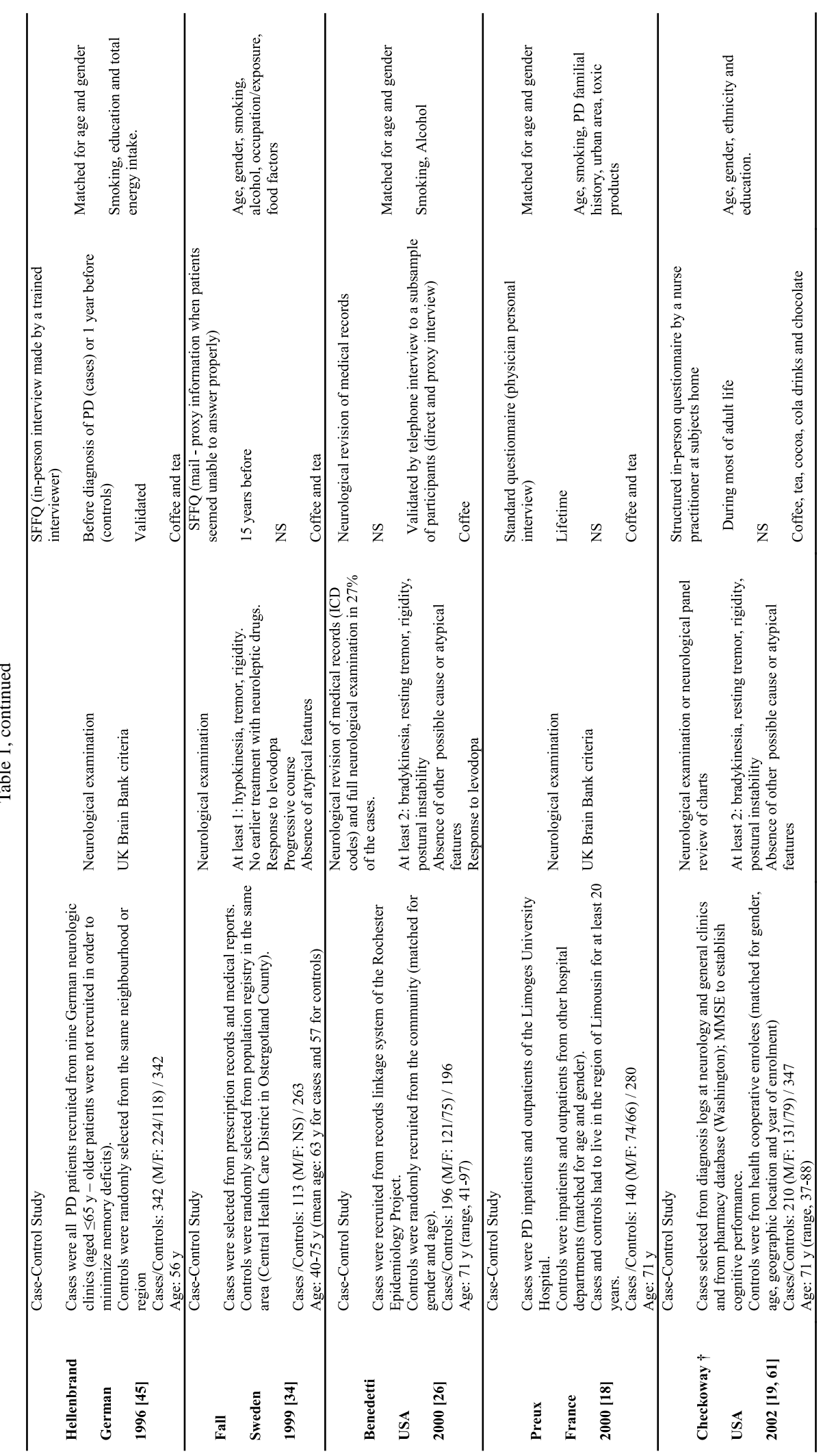




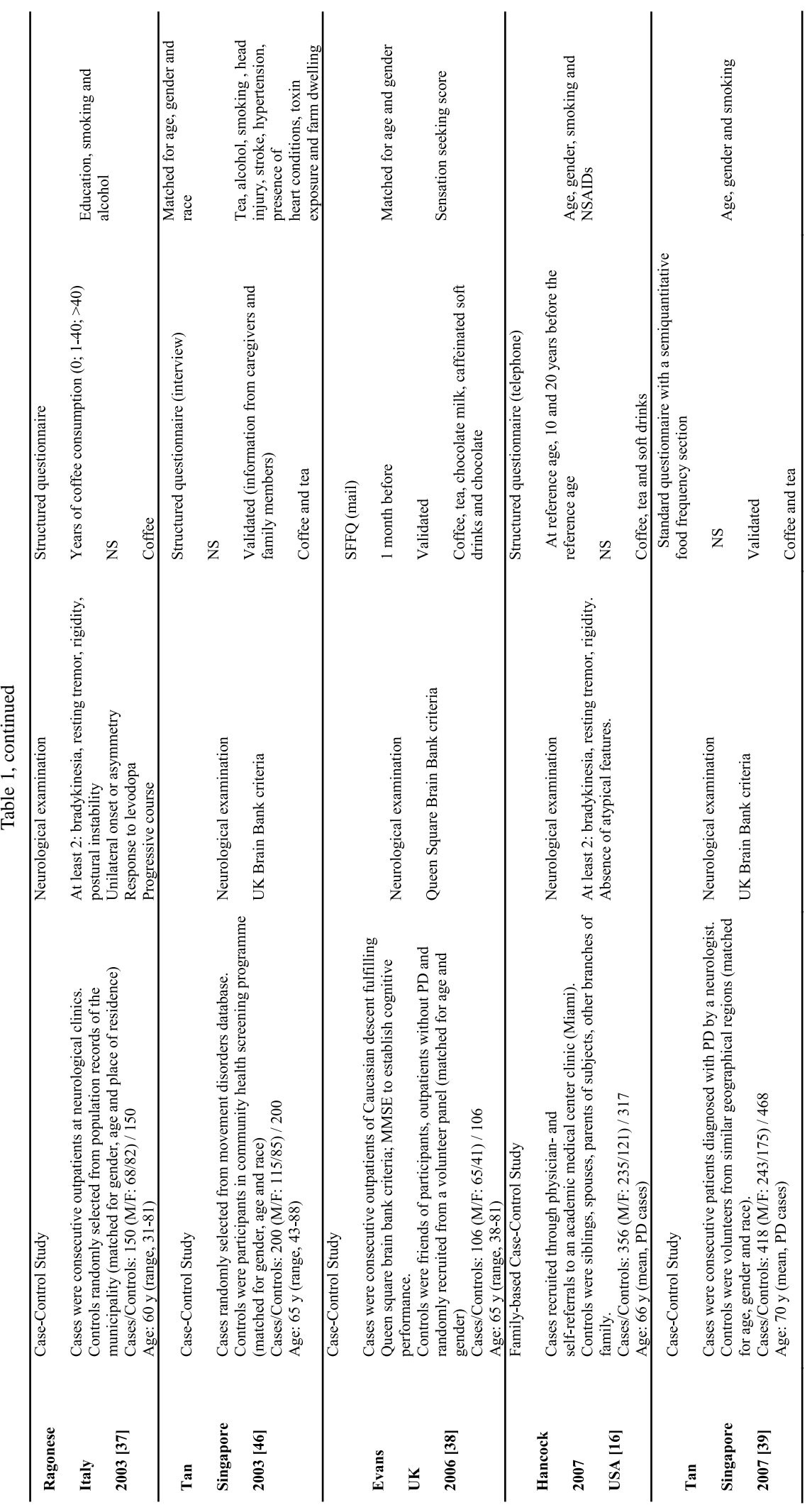




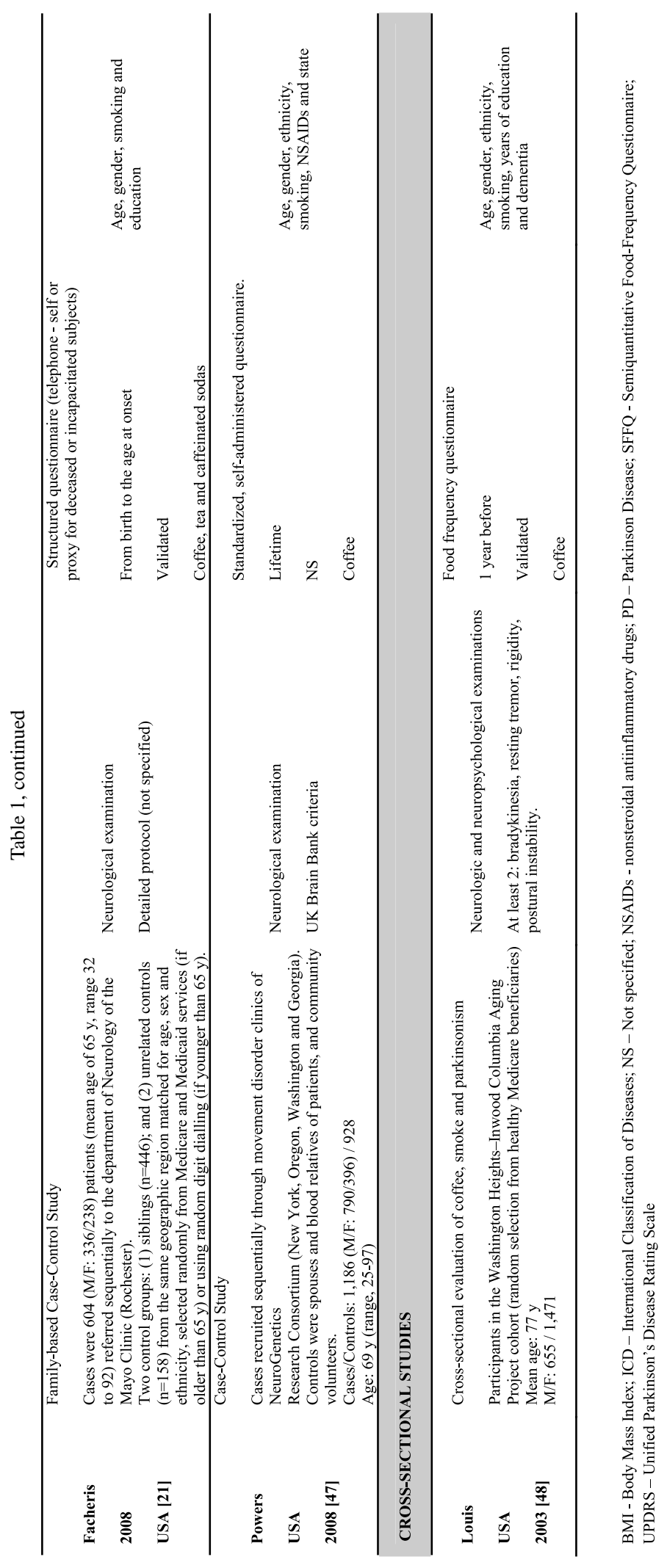




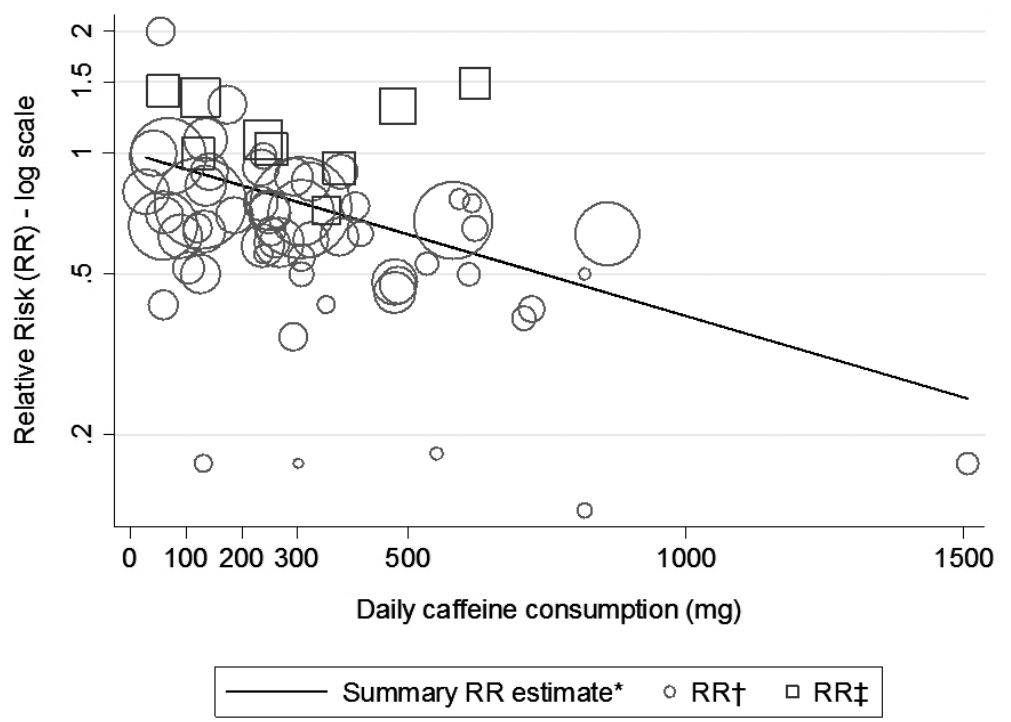

Fig. 5. Dose-response relation for the association between caffeine intake and the risk of Parkinson's disease. Legend: * Summary RR estimated by weighted least squares regression; $\dagger$ RRs for the comparison of each category of exposure with the reference category, obtained from each individual study; $\ddagger$ RRs for the comparison of each category of exposure with the reference category, obtained from the studies providing stratum-specific estimates for women under Hormonal Replacement Therapy [29,33].

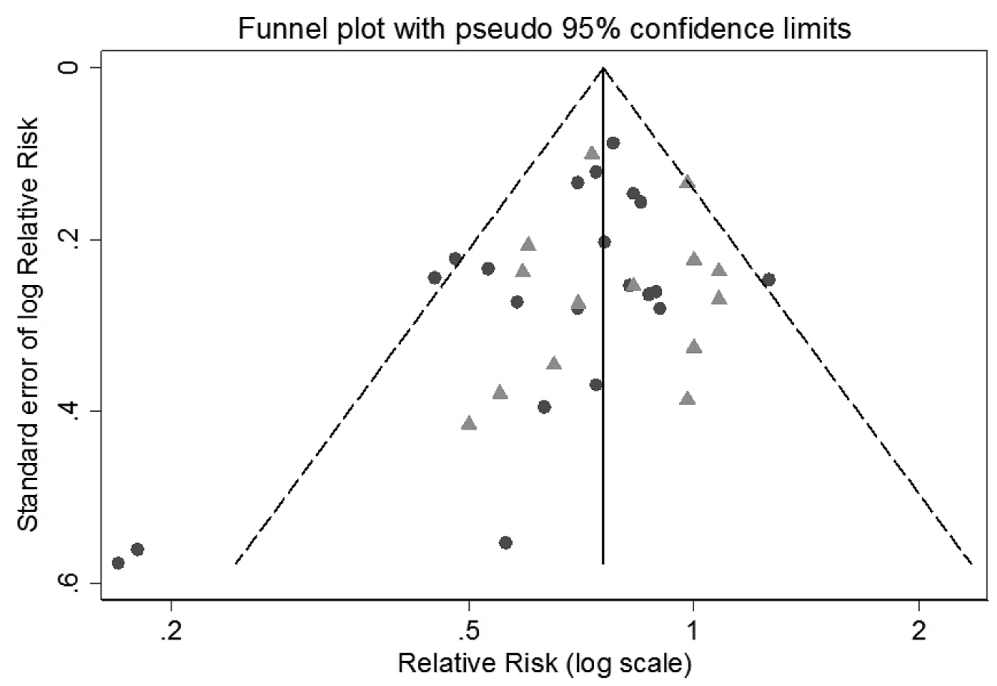

Fig. 6. Meta-analysis funnel plot, including the most precise Relative Risk estimates from each individual study. Legend: Circles case-control/cross-sectional studies; Triangles - cohort/nested case-control studies.

estimated mean age of the participants at the time of baseline evaluation ranged from 42 to 77 years [33].

Different sources of caffeine were accounted for in the reports reviewed, and the results used for metaanalysis refer to coffee consumption in most studies ( $n=15$ ), to coffee and tea consumption in 5 studies, and 6 studies extended exposure assessment to all caffeinated beverages or caffeinated beverages and products containing chocolate. Seventeen out of 25 studies provided RR estimates for different categories of exposure, with an estimated daily exposure to caffeine ranging from $27.4 \mathrm{mg}$ to $1507 \mathrm{mg}$, and the reference categories including different proportions of non-caffeine consumers and consumers of different amounts of caffeine. From one study we used the RR estimate for the variation in the consumption of one cup of coffee per day. The remaining studies only compared drinkers with non-drinkers. 
The clinical diagnosis of PD, based on a set of predefined clinical criteria, was the outcome in most studies. Information obtained from medical records and national medication or inpatient databases were occasionally considered as a complementary source in 6 studies [19, $20,28,29,36,40]$, as well as from death certificates in 4 studies $[20,28,33,36]$. In two studies $[16,40]$ some patients had PD defined by self report and not confirmed by a clinical diagnosis, death certificates or medical records. One study [22] assessed PD mortality as the sole outcome.

Regarding potential confounding factors, smoking was considered taken into account in 7 studies $[15,16$, 19,20,31,32,38]. Exposure to heavy metals and use of pesticides or herbicides was accounted for by 2 authors $[18,46]$. Age and gender were controlled for in all studies except that by Ragonese et al. [37], either by stratified analysis, matching or multiple regression.

\section{Meta-analyses}

The summary RR for the association between caffeine intake and PD was 0.75 (95\%CI: 0.68-0.82), with low to moderate heterogeneity $\left(\mathrm{I}^{2}=28.8 \%\right)$. The summary RR estimates were homogeneous $\left(\mathrm{I}^{2}=8.1 \%\right)$ and slightly higher among the cohort/nested case-control studies, and the $\mathrm{I}^{2}$ was $37.9 \%$ among the case-control studies (Fig. 3). The negative association was weaker when only women were considered for analysis (summary $\mathrm{RR}=0.86,95 \% \mathrm{CI}$ : 0.73-1.02, 9 estimates from 7 studies, $\mathrm{I}^{2}=12.9 \%$ ) than when only men were considered for analysis (summary $\mathrm{RR}=0.72$, 95\% CI: $0.65-0.81,9$ estimates from 9 studies, $\mathrm{I}^{2}=0.0 \%$ ) or both genders were considered (summary $\mathrm{RR}=0.68$, 95\%CI: $0.57-0.81,17$ estimates from 16 studies, $\mathrm{I}^{2}=$ $50.3 \%$ ).

The search date of the previous most recent systematic review on the risk of $P D$ and caffeine exposure was 2001 [17]. The results of the cumulative meta-analysis (Fig. 4) show that since year 2001 the number of studies on this topic nearly doubled, corresponding to 14 new published studies (5 cohort/nested case-control and 9 case-control/cross-sectional studies). The results of these new studies allowed us to calculate a total of 23 RR estimates that were included in the present metaanalysis and confirmed the observation of a consistent and robust association between caffeine intake and PD. The summary RR was 0.72 (95\%CI: $0.61-0.84)$ at the end of 2001 and is currently 0.75 (95\%CI: 0.68 $0.82)$, with no meaningful variation in heterogeneity ( $\mathrm{I}^{2}: 26.6 \%$ in 2001 vs. $32.6 \%$ in 2008 ).
A linear relation was observed between levels of exposure to caffeine and the RR estimates (Fig. 5), corresponding to a summary RR of 0.76 (95\%CI: 0.72-0.80) per $300 \mathrm{mg}$ increase in caffeine intake, with moderate heterogeneity $\left(\mathrm{I}^{2}=35.1 \%\right)$. Excluding the estimates corresponding to women under HRT from the studies by Ascherio et al. [22,33], the heterogeneity decreased $\left(\mathrm{I}^{2}=27.6 \%\right)$.

\section{Publication bias}

The visual inspection of the funnel plot (Fig. 6) suggests that case-control/cross-sectional low precision studies yielding a positive association between caffeine intake and PD may be underrepresented in our metaanalysis, which is confirmed by the Egger's regression asymmetry test ( $p=0.053$ ) and the Begg adjusted rank correlation test $(p=0.037)$. On the other hand, for cohort/nested case-control studies, the funnel plot is symmetric and there is no evidence of statistically significant publication bias (Egger's regression asymmetry test: $p=0.821$; Begg adjusted rank correlation test: $p=0.412$ ).

\section{DISCUSSION}

The present meta-analysis shows a $25 \%$ reduction in risk of PD among caffeine consumers. The results also indicate a linear dose-response relation, with higher intakes of caffeine being associated with a lower risk of PD.

From a biological point of view, caffeine $(1,3,7-$ trimethylxanthine) and its major metabolite, paraxanthine (1,7-dimethylxanthine), are antagonists of the adenosine A2A receptors. The expression of these receptors in the brain is particularly prominent in the striatum, which is the target of the dopaminergic neurons that degenerate in PD. Similar to other more specific A2A antagonists, caffeine attenuates neurotoxicity in experimental animal models of PD [49,50]. A recent study by Nakaso and collaborators provided further evidence for a possible neuroprotective effect of caffeine, showing that caffeine activates specific neuroprotection signaling pathways and prevents apoptotic cell death in a PD model using human dopaminergic neuroblastoma cells [51]. Therefore, there is a plausible rational biological mechanism based on the pharmacological actions of caffeine for the inverse association between coffee drinking and PD found in several epidemiological studies. 
The primary candidate component that is believed to be responsible for the neuroprotective effect of coffee is caffeine. In fact, a negative association has also been reported for other non-coffee sources of caffeine, such as tea [46], but not for decaffeinated coffee [28]. However, coffee is a complex chemical mixture reported to contain more than a thousand different chemicals, including carbohydrates, lipids, nitrogenous compounds, vitamins, minerals, alkaloids, and phenolic compounds [52]. Thus, the possibility exists that other components of coffee or tea may also play a role. However, our systematic review was designed to test the effect of caffeine on the risk of PD under assumption that coffee is the main contributor to caffeine intake, and the specific effect of other caffeine containing beverages, such as tea, was not evaluated.

The negative association between caffeine intake and PD was consistent throughout different methodological approaches. Unlike those observed for cohort designs, the results from case-control/cross-sectional studies were somewhat heterogeneous, but consistently pointed to a protective effect, despite the observation that the strength of the association differed substantially across studies. Publication bias seems to have occurred for case-control/cross-sectional, but not for cohort/nested case-control studies, which may contribute to explain the stronger negative association observed among the former. Moreover, the homogeneity across results of cohort designs probably reflects a lower potential for bias with this methodological approach. Control selection is more likely to be biased in hospital-based case-control studies. Patients with PD may have an associated cognitive impairment [53], especially among older individuals, and this makes information bias more likely when exposure assessment is retrospective and exposure information is not collected from proxies. Also, patients with motor disability, such as in PD, may be less likely to drink coffee and this can only be accounted for with prospective designs or assessing exposure before the occurrence of the disease.

It has been suggested that PD patients may have a premorbid personality which may be responsible for particular addictive personality characteristics [54-58]. In PD, the progressive degeneration of the striatum with low endogenous dopamine and serotonin levels may lead to a low sensation seeking behavior (cause-effect bias) [59]. PD patients may therefore be less prone to smoke and drink coffee and alcohol, all lifestyle confounders with a potential neuroprotective or symptomatic effect in PD. Evans and coworkers [38] ad- dressed this issue and raised the possibility of an existing neurobiological link between low sensationseeking trait, which may underlie the parkinsonian personality, and the hypothetical protective effect of coffee in Parkinson's disease.

Cohort designs are less prone to information bias, but also have potential limitations related to the enrollment of non-inception cohorts and resulting from incomplete follow-up. Another potential source of bias is the definition of PD cases because of the lack of information regarding PD diagnoses in medical records and death certificates. Bias may also arise from exposure classification and quantification of coffee/caffeine consumption due to the different methods used in the studies, the low accuracy (recall bias) and reproducibility of the quantitative questionnaires, and the high variability of caffeine concentrations in coffee beverages.

It has been recognized that smokers have a lower risk of PD [17] and confounding by smoking habits is therefore an inherent problem when addressing the association between caffeine and PD. The majority of results available, however, were adjusted for smoking and other potential sources of bias, which makes confounding unlikely to be responsible for our conclusions.

The methodological options in our meta-analysis also need to be discussed. From studies presenting RRs for different categories of exposure we selected the most precise estimates to compute the summary RR for caffeine consumers vs. non-consumers, which allowed us to include all the available studies in the analysis. The precision of the individual RR estimates is not dependent on the direction of the association, and with this criterion the selection of the exposures corresponding to the largest number of participants is the most likely. However, if the categories of exposure in each individual study are defined to include a similar number of participants per group, this criterion leads to the selection of the estimates reflecting the weaker associations. This contributed to a slight underestimation of the summary RR, as well as an overestimation of homogeneity, especially for the cohort studies among which the definition of exposure categories with a similar number of participants was more frequent. The precision of the summary estimates, however, is underestimated by considering only part of the overall sample from each study in the meta-analysis.

For trend estimation we conducted a weighted linear regression adjusted through the origin, which implies the assumption of independence between all categories of exposure, an assumption that within each study is not met because all risk estimates depend on a common 
referent group, ultimately leading to an underestimation of the slope variance. This contributes to spurious precision of our estimates but allows the computation of point estimates less prone to bias as it allows inclusion of most studies providing information for different categories of exposure. The use of a method that allows the correction for the lack of independence across RR estimates for different exposures would lead to the exclusion of some of the studies, as it requires more information than is provided by many studies [60].

A meta-analysis conducted by Hernán et al., published in 2002, concluded that smoking habits and coffee intake were independently associated with a lower risk of Parkinson's disease [17]. Despite the different options for meta-analysis, our review included nearly twice more individual studies and reaches robust conclusions that confirm the negative association between caffeine and PD. Also, the present meta-analysis adds to the previous one by confirming a linear dose-response relation, as previously suggested by Hernán and colleagues. Recent studies aiming to evaluate interactions with hormonal replacement therapy in women or hepatic caffeine metabolization were included [22,33,39], contributing to a broader view of the problem.

Ascherio and collaborators suggested gender differences in the relation of caffeine intake and the risk of PD: in men, a strong inverse association was found, whereas in women a U-shaped relationship was observed, with the lowest risk occurring at moderate intakes [29]. These authors further investigated this difference in two different cohorts and found an interaction between the use of postmenopausal hormones and caffeine intake in the risk of PD, with an increased risk among women on hormonal replacement therapy with a high caffeine intake $[22,33]$. The use of postmenopausal estrogens seems to modify the effects of caffeine on the risk of PD, although the reasons for this interaction are not yet clear.

The individual variability in the metabolism of coffee compounds related to genetic polymorphisms was also recently addressed [39]. The main endogenous system responsible for caffeine metabolism in humans is the cytochrome P450 1A2 (CYP 1A2). The study conducted by Tan and coworkers stratified the results for CYP 1A2 genetic polymorphism and demonstrated a similar dose-dependent PD protective effect of caffeine in individuals with fast and slow metabolizing status [39].

In conclusion, our data confirm an inverse association between caffeine intake and the risk of PD, with a dose-response relation, and more consistency in co- hort studies and among men, which cannot be fully explained by bias or uncontrolled confounding. The understanding of the mechanisms for the protective effect of caffeine exposure warrants further investigation in PD.

\section{DISCLOSURE STATEMENTS}

Authors' disclosures available online (http://www.jalz.com/disclosures/view.php?id=266).

\section{REFERENCES}

[1] de Lau LM, Breteler MM (2006) Epidemiology of Parkinson's disease. Lancet Neurol 5, 525-535.

[2] Lang AE, Lozano AM (1998) Parkinson's disease. First of two parts. N Engl J Med 339, 1044-1053.

[3] Langston JW (1998) Epidemiology versus genetics in Parkinson's disease: progress in resolving an age-old debate. Ann Neurol 44(Suppl 1), S45-52.

[4] Tan EK, Khajavi M, Thornby JI, Nagamitsu S, Jankovic J, Ashizawa T (2000) Variability and validity of polymorphism association studies in Parkinson's disease. Neurology 55, 533538.

[5] Tanner CM, Ottman R, Goldman SM, Ellenberg J, Chan P, Mayeux R, Langston JW (1999) Parkinson disease in twins: an etiologic study. JAMA 281, 341-346.

[6] Sveinbjörnsdottir S, Hicks AA, Jonsson T, Pétursson $H$, Guğmundsson G, Frigge ML, Kong A, Gulcher JR, Stefansson K (2000) Familial aggregation of Parkinson's disease in Iceland. $N$ Engl J Med 343, 1765-1770.

[7] Racette BA, Tabbal SD, Jennings D, Good L, Perlmutter JS, Evanoff B (2005) Prevalence of parkinsonism and relationship to exposure in a large sample of Alabama welders. Neurology 64, 230-235.

[8] Stern M, Dulaney E, Gruber SB, Golbe L, Bergen M, Hurtig H, Gollomp S, Stolley P (1991) The epidemiology of Parkinson's disease. A case-control study of young-onset and old-onset patients. Arch Neurol 48, 903-907.

[9] Ascherio A, Chen H, Weisskopf MG, O'Reilly E, McCullough ML, Calle EE, Schwarzschild MA, Thun MJ (2006) Pesticide exposure and risk for Parkinson's disease. Ann Neurol 60, 197-203.

[10] Gorell JM, Johnson CC, Rybicki BA, Peterson EL, Richardson RJ (1998) The risk of Parkinson's disease with exposure to pesticides, farming, well water, and rural living. Neurology 50, 1346-1350.

[11] Chen H, Zhang SM, Schwarzschild MA, Hernán MA, Ascherio A (2005) Physical activity and the risk of Parkinson disease. Neurology 64, 664-669.

[12] Chade AR, Kasten M, Tanner CM (2006) Nongenetic causes of Parkinson's disease. J Neural Transm Suppl 70, 147-151.

[13] Logroscino G (2005) The role of early life environmental risk factors in Parkinson disease: what is the evidence? Environ Health Perspect 113, 1234-1238.

[14] Dorn HF (1959) Tobacco consumption and mortality from cancer and other diseases. Public Health Rep 74, 581-593. 
[15] Nefzger MD, Quadfasel FA, Karl VC (1968) A retrospective study of smoking in Parkinson's disease. Am J Epidemiol 88, 149-158.

[16] Hancock DB, Martin ER, Stajich JM, Jewett R, Stacy MA, Scott BL, Vance JM, Scott WK (2007) Smoking, caffeine, and nonsteroidal anti-inflammatory drugs in families with Parkinson disease. Arch Neurol 64, 576-580.

[17] Hernán MA, Takkouche B, Caamaño-Isorna F, Gestal-Otero JJ (2002) A meta-analysis of coffee drinking, cigarette smoking, and the risk of Parkinson's disease. Ann Neurol 52, 276-284.

[18] Preux PM, Condet A, Anglade C, Druet-Cabanac M, Debrock C, Macharia W, Couratier P, Boutros-Toni F, Dumas M (2000) Parkinson's disease and environmental factors. Matched casecontrol study in the Limousin region, France. Neuroepidemiology 19, 333-337.

[19] Checkoway H, Powers K, Smith-Weller T, Franklin GM, Longstreth WT Jr, Swanson PD (2002) Parkinson's disease risks associated with cigarette smoking, alcohol consumption, and caffeine intake. Am J Epidemiol 155, 732-738.

[20] Wirdefeldt K, Gatz M, Pawitan Y, Pedersen NL (2005) Risk and protective factors for Parkinson's disease: a study in Swedish twins. Ann Neurol 57, 27-33.

[21] Facheris MF, Schneider NK, Lesnick TG, de Andrade M, Cunningham JM, Rocca WA, Maraganore DM (2008) Coffee, caffeine-related genes, and Parkinson's disease: a case-control study. Mov Disord 23, 2033-2040.

[22] Ascherio A, Weisskopf MG, O'Reilly EJ, McCullough ML, Calle EE, Rodriguez C, Thun MJ (2004) Coffee consumption, gender, and Parkinson's disease mortality in the cancer prevention study II cohort: the modifying effects of estrogen. Am J Epidemiol 160, 977-984.

[23] Hu G, Bidel S, Jousilahti P, Antikainen R, Tuomilehto J (2007) Coffee and tea consumption and the risk of Parkinson's disease. Mov Disord 22, 2242-2248.

[24] Kandinov B, Giladi N, Korczyn AD (2007) The effect of cigarette smoking, tea, and coffee consumption on the progression of Parkinson's disease. Parkinsonism Relat Disord 13, 243-245.

[25] Simon DK, Swearingen CJ, Hauser RA, Trugman JM, Aminoff MJ, Singer C, Truong D, Tilley BC; NET-D Investigators (2008) Caffeine and progression of Parkinson disease. Clin Neuropharmacol 31, 189-196.

[26] Benedetti MD, Bower JH, Maraganore DM, McDonnell SK, Peterson BJ, Ahlskog JE, Schaid DJ, Rocca WA (2000) Smoking, alcohol, and coffee consumption preceding Parkinson's disease: a case-control study. Neurology 55, 1350-1358.

[27] Kandinov B, Giladi N, Korczyn AD (2009) Smoking and tea consumption delay onset of Parkinson's disease. Parkinsonism Relat Disord 15, 41-46.

[28] Ross GW, Abbott RD, Petrovitch H, Morens DM, Grandinetti A, Tung KH, Tanner CM, Masaki KH, Blanchette PL, Curb JD, Popper JS, White LR (2000) Association of coffee and caffeine intake with the risk of Parkinson disease. JAMA 283, 2674-2679.

[29] Ascherio A, Zhang SM, Hernán MA, Kawachi I, Colditz GA, Speizer FE, Willett WC (2001) Prospective study of caffeine consumption and risk of Parkinson's disease in men and women. Ann Neurol 50, 56-63.

[30] Morano A, Jiménez-Jiménez FJ, Molina JA, Antolín MA (1994) Risk-factors for Parkinson's disease: case-control study in the province of Cáceres, Spain. Acta Neurol Scand 89, $164-170$

[31] Jiménez-Jiménez FJ, Mateo D, Giménez-Roldan S (1992) Premorbid smoking, alcohol consumption, and coffee drinking habits in Parkinson's disease: a case-control study. Mov Disord 7, 339-344.

[32] Haack DG, Baumann RJ, McKean HE, Jameson HD, Turbek JA (1981) Nicotine exposure and Parkinson disease. Am J Epidemiol 114, 191-200.

[33] Ascherio A, Chen H, Schwarzschild MA, Zhang SM, Colditz GA, Speizer FE (2003) Caffeine, postmenopausal estrogen, and risk of Parkinson's disease. Neurology 60, 790-795.

[34] Fall PA, Fredrikson M, Axelson O, Granérus AK (1999) Nutritional and occupational factors influencing the risk of Parkinson's disease: a case-control study in southeastern Sweden. Mov Disord 14, 28-37.

[35] Fink JS, Bains LA, Beiser A, Seshadri S, Wolf PA (2001) Caffeine intake and the risk of incident Parkinson's disease: the Framingham Study. Mov Disord 16, 984.

[36] Paganini-Hill A (2001) Risk factors for parkinson's disease: the leisure world cohort study. Neuroepidemiology 20, 118124.

[37] Ragonese P, Salemi G, Morgante L, Aridon P, Epifanio A, Buffa D, Scoppa F, Savettieri G (2003) A case-control study on cigarette, alcohol, and coffee consumption preceding Parkinson's disease. Neuroepidemiology 22, 297-304.

[38] Evans AH, Lawrence AD, Potts J, MacGregor L, Katzenschlager R, Shaw K, Zijlmans J, Lees AJ (2006) Relationship between impulsive sensation seeking traits, smoking, alcohol and caffeine intake, and Parkinson's disease. J Neurol Neurosurg Psychiatry 77, 317-321.

[39] Tan EK, Chua E, Fook-Chong SM, Teo YY, Yuen Y, Tan L, Zhao Y (2007) Association between caffeine intake and risk of Parkinson's disease among fast and slow metabolizers. Pharmacogenet Genomics 17, 1001-1005.

[40] Tan LC, Koh WP, Yuan JM, Wang R, Au WL, Tan JH, Tan EK, Yu MC (2008) Differential effects of black versus green tea on risk of Parkinson's disease in the Singapore Chinese Health Study. Am J Epidemiol 167, 553-560.

[41] Higgins JP, Thompson SG (2002) Quantifying heterogeneity in a meta-analysis. Stat Med. 21, 1539-1558.

[42] Begg CB, Mazumdar M (1994) Operating characteristics of a rank correlation test for publication bias. Biometrics 50, 10881101.

[43] Egger M, Davey Smith G, Schneider M, Minder C (1997) Bias in meta-analysis detected by a simple, graphical test. $B M J \mathbf{3 1 5}$, 629-634.

[44] Abbott RD, Ross GW, White LR, Sanderson WT, Burchfiel CM, Kashon M, Sharp DS, Masaki KH, Curb JD, Petrovitch H (2003) Environmental, life-style, and physical precursors of clinical Parkinson's disease: recent findings from the Honolulu-Asia Aging Study. J Neurol 250 (Suppl 3), 30-39.

[45] Hellenbrand W, Seidler A, Boeing H, Robra BP, Vieregge P, Nischan P, Joerg J, Oertel WH, Schneider E, Ulm G (1996) Diet and Parkinson's disease I: A possible role for the past intake of specific foods and food groups. Results from a selfadministered food frequency questionnaire in a case-control study. Neurology 47, 636-643.

[46] Tan EK, Tan C, Fook-Chong SM, Lum SY, Chai A, Chung H, Shen H, Zhao Y, Teoh ML, Yih Y, Pavanni R, Chandran VR, Wong MC (2003) Dose-dependent protective effect of coffee, tea, and smoking in Parkinson's disease: a study in ethnic Chinese. J Neurol Sci 216, 163-167.

[47] Powers KM, Kay DM, Factor SA, Zabetian CP, Higgins DS, Samii A, Nutt JG, Griffith A, Leis B, Roberts JW, Martinez ED, Montimurro JS, Checkoway H, Payami H (2008) Combined effects of smoking, coffee, and NSAIDs on Parkinson's disease risk. Mov Disord 23, 88-95. 
[48] Louis ED, Luchsinger JA, Tang MX, Mayeux R (2003) Parkinsonian signs in older people: prevalence and associations with smoking and coffee. Neurology 61, 24-28.

[49] Schwarzschild MA, Xu K, Oztas E, Petzer JP, Castagnoli K, Castagnoli N Jr, Chen JF (2003) Neuroprotection by caffeine and more specific A2A receptor antagonists in animal models of Parkinson's disease. Neurology 61(Suppl 6), S55-61.

[50] Kalda A, Yu L, Oztas E, Chen JF (2006) Novel neuroprotection by caffeine and adenosine $\mathrm{A}(2 \mathrm{~A})$ receptor antagonists in animal models of Parkinson's disease. J Neurol Sci 248, 9-15.

[51] Nakaso K, Ito S, Nakashima K (2008) Caffeine activates the PI3K/Akt pathway and prevents apoptotic cell death in a Parkinson's disease model of SH-SY5Y cells. Neurosci Lett 432, 146-150.

[52] Higdon JV, Frei B (2006) Coffee and health: a review of recent human research. Crit Rev Food Sci Nutr 46, 101-123.

[53] Aarsland D, Kurz MW (2010) The epidemiology of dementia associated with Parkinson disease. J Neurol Sci 289, 18-22.

[54] Paulson GW, Dadmehr N (1991) Is there a premorbid personality typical for Parkinson's disease? Neurology 41(Suppl 2), 73-76.

[55] Ishihara L, Brayne C (2006) What is the evidence for a premorbid parkinsonian personality: a systematic review. Mov
Disord 21, 1066-1072.

[56] Ward CD, Duvoisin RC, Ince SE, Nutt JD, Eldridge R, Calne DB, Dambrosia J (1984) Parkinson's disease in twins. Adv Neurol 40, 341-344.

[57] Kaasinen V, Nurmi E, Bergman J, Eskola O, Solin O, Sonninen P, Rinne JO (2001) Personality traits and brain dopaminergic function in Parkinson's disease. Proc Natl Acad Sci U S A 98, 13272-13277.

[58] Tomer R, Aharon-Peretz J (2004) Novelty seeking and harm avoidance in Parkinson's disease: effects of asymmetric dopamine deficiency. J Neurol Neurosurg Psychiatry 75, 972975.

[59] Marder K, Logroscino G (2002) The ever-stimulating association of smoking and coffee and Parkinson's disease. Ann Neurol 52, 261-262.

[60] Greenland S, Longnecker MP (1992) Methods for trend estimation from summarized dose-response data, with applications to meta-analysis. Am J Epidemiol 135, 1301-1309.

[61] Anderson C, Checkoway H, Franklin GM, Beresford S, SmithWeller T, Swanson PD (1999) Dietary factors in Parkinson's disease: the role of food groups and specific foods. Mov Disord 14, 21-27. 